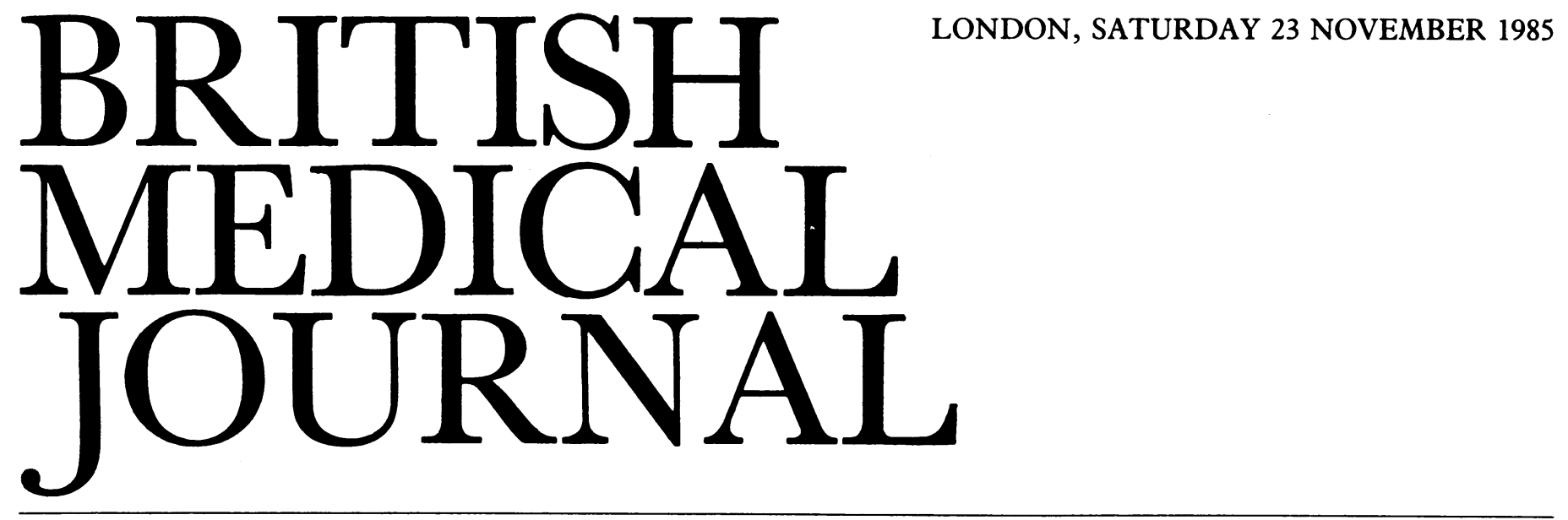

\title{
Probability analysis in the diagnosis of coronary artery disease
}

Angina, the pain that occurs during myocardial ischaemia, is usually a manifestation of coronary artery disease. Early diagnosis is important not only because effective treatment is available for controlling symptoms but also because surgical intervention can now improve prognosis in large subgroups of patients. ${ }^{1-3}$ Definitive diagnosis of conary artery disease is generally taken to require coronary angiography, but the investigation is expensive and facilities are limited. Thus coronary angiography should be restricted to carefully selected patients after critical evaluation of the clinical history and the results of non-invasive investigation.

In the clinical evaluation of patients with chronic chest pain the diagnosis of coronary artery disease is a probability judgment based largely on the character of the symptoms and the age and sex of the patient. The physician usually makes this judgment intuitively, recognising that typical symptoms of angina, advancing age, and male sex independently heighten the probability of coronary artery disease. Diamond and Forrester have presented a quantitative assessment of diagnostic probability using pooled data from clinical and postmortem studies. ${ }^{4}$ Though the analysis may not be strictly applicable to European populations, it provides a useful guide to the risk of coronary artery disease in well defined clinical subgroups. Thus in patients with "typical angina" the risk is about $90 \%$ for men and women older than 40 and 60 respectively. Conversely, "non-anginal chest pain" carries a risk of less than $10 \%$ for men and women younger than 40 and 60 respectively. The risk is also very low in women younger than 40 with "atypical angina." In other age and sex categories with non-anginal chest pain, atypical angina, or typical angina the probability of coronary artery disease lies between these extremes.

Probability estimates of coronary artery disease based on simple clinical criteria exert an important influence on the diagnostic yield of non-invasive investigation. ${ }^{4}$ The most widely used non-invasive tests are exercise electrocardiography and radionuclide perfusion imaging. Downward displacement of the ST segment on exercise or scintigraphic perfusion defects (with reversal of these abnormalities during rest) may indicate myocardial ischaemia due to coronary artery disease. Yet because these tests are less than perfect Bayes's theorem states that their predictive value-defined by sensitivity and specificity - is variable and depends on the probability of coronary artery disease in the population under study. ${ }^{56}$ Thus a test result positive for myocardial ischaemia has greatest predictive value when the pretest probability of coronary artery disease is high. A negative result, on the other hand, has greatest predictive value when the pretest probability of coronary artery disease is low. ${ }^{4}$

Bayes's theorem has important implications for the noninvasive diagnosis of coronary artery disease. ${ }^{7} \mathrm{~A}$ positive test result (electrocardiographic or radionuclide) in a 50 year old man with typical angina, for example, is strongly predictive of coronary artery disease-but it contributes little new diagnostic information because the pretest probability of coronary artery disease is already very high. Similarly, the high incidence of false negative results in patients of this type diminishes the diagnostic value of a negative result. When the pretest probability of coronary artery disease is very low non-invasive testing is also of limited value. In the 30 year old woman with atypical angina, for example, a misleading false positive result is very common, while a negative finding merely serves to confirm the clinical judgment. ${ }^{8-10}$

The clinical application of formal probability analysis has been recommended by certain workers, ${ }^{11}$ but this has not been shown to enhance diagnostic accuracy above that achieved by the cardiologist. ${ }^{1213}$ Nevertheless, a working knowledge of the principles permits a more rational approach to clinical decision making, which may substantially reduce the load of unhelpful investigations and improve the cost effectiveness of the diagnostic process. ${ }^{14}$ is

If an evaluation of the symptoms, age, and sex of the patient indicates either a very high $(>90 \%)$ or very low $(<10 \%)$ probability of coronary artery disease non-invasive testing is unlikely to be of diagnostic value because almost regardless of the result it will not substantially affect that probability judgment. If the probability of coronary artery disease lies between these poles of confidence non-invasive testing should always be undertaken. Negative results usually lower the probability of coronary artery disease to the point where further cardiac investigation is unnecessary. ${ }^{16}$ The temptation to proceed to coronary angiography should then be resisted, because the bulk of evidence indicates that a normal angiogram is of little therapeutic value to patients of this type. ${ }^{17-19}$ Positive results, on the other hand, increase the probability of coronary artery disease closer to that of the middle aged man or elderly woman with typical angina. At this level of probability a decision must then be made whether to proceed to coronary angiography in order to obtain definitive diagnostic information.

It is not practicable to undertake coronary angiography in every patient judged to have a high probability of coronary 
artery disease merely to confirm the diagnosis. Angiography is essential for the preoperative evaluation of patients being considered for bypass surgery and should be reserved for patients most likely to benefit from treatment of this type. This includes those with severe symptoms which fail to respond adequately to antianginal drugs. ${ }^{20}$ Unfortunately, severity of symptoms is not closely related to the extent of coronary artery disease, ${ }^{21}$ and selection of patients for angiography on this basis alone tends to ignore the proved benefit of bypass surgery (in terms of mortality) for subgroups with triple vessel or left main artery disease. ${ }^{12}$ Exercise electrocardiography has been recommended for identification of these high risk subgroups: severely restricted exercise tolerance, exaggerated ST segment depression, and an abnormal response of the blood pressure are predictors of extensive coronary artery disease and a poor prognosis. ${ }^{22-24}$

Unfortunately, the specificity of these predictive variables is not matched by a similar level of sensitivity, ${ }^{4}$ and reliance on non-invasive tests for prognostic guidance ensures that some high risk patients will be overlooked. Indeed, only coronary angiography itself can accurately identify these patients at high risk and provide a less arbitrary selection standard for coronary bypass surgery. At present, resources are not available to underwite a policy of angiography for all patients with suspected coronary artery disease. ${ }^{25}$ Rigorous selection is therefore essential based on an individualised assessment of diagnostic probability and the predicted benefit of bypass surgery.

ADAM D TIMMIS

Senior Registrar,

Department of Cardiology,

Guy's Hospital,

London SE1 9RT

1 European Coronary Surgery Study Group. Long-term results of prospective randomised study of coronary artery bypass surgery in stable angina pectoris. Lancet 1982;ii:1173-80.

2 Veterans Administration Coronary Artery Bypass Surgery Cooperative Study Group. Eleven-year survival in Veterans Administration randomised trial of coronary bypass surgery for stable angina. N Engl f Med 1984;311:1333-9.

3 Passamani E, Davis KB, Gillespie MJ, Killip T, and CASS Principal Investigators and their assamani E, Davis KB, Gillespie MJ, Killip T, and CASS Principal Investigators and their
Associates. A randomised trial of coronary artery bypass surgery. Survival of patients with a low Associates. A randomised trial of coronary artery bypa

5 Ledley RGF, Lusted LB. Reasoning foundations of medi : diagnosis. Science 1959; 130:9-13.

6 Vecchio TJ. Predictive value of a single diagnostic test in unselected populations. N Engl I Med 1966;274:1171-3.

7 Epstein SE. Implications of probability analysis on the strategy used for noninvasive detection of coronary artery disease. Role of single or combined use of exercise electrocardiographic testing, radionuclide cineangiography and myocardial perfusion imaging. Am $\mathcal{f}$ Cardiol 1980;46:491-9.

8 Detry J-MR, Kapita BM, Cosyns J, Sottiaux B, Brasseur LA, Rousseau MF. Diagnostic value of history and maximal exercise electrocardiography in men and women suspected of coronary heart disease. Circulation 1977;56:756-61.

9 Melin JA, Piret LJ, Vanbutsele RJM, et al. Diagnostic value of exercise electrocardiography and thallium myocardial scintigraphy in patients without previous myocardial infarction: a Bayesia approach. Circulation 1981;63:1019-24.

10 Detrand R, Yiannikas J, Salcedo EE, et al. Bayesian probability analysis: a prospective demonstration of its clinical utility in diagnosing coronary disease. Circulation 1984;69:541-7.

11 Wagner HN Jr. Bayes' theorem: an idea whose time has come? Am $f$ Cardiol 1982;49:875-7.

12 Hlatky M, Botvinick E, Brundage B. Diagnostic accuracy of cardiologists compared with probability calculations using Bayes' rule. Am f Cardiol 1982;49:1927-31.

probability calculations using Bayes' rule. Am f Cardiol 1982;49:1927-31.
13 Diamond GA, Forrester JS, Hirsch M, et al. Application of conditional probability analysis to the Diamond GA, Forrester JS, Hirsch M, et al. Application of conditional probabity
clinical diagnosis of coronary artery disease. $\mathcal{F}$ Clin Invest 1980;65:1210-21.

14 Patterson RE, Eng C, Horowitz SF, Gorlin R, Goldstein SR. Bayesian comparison of costeffectiveness of different clinical approaches to diagnose coronary artery disease. Foumal of the American College of Cardiology 1984;4:278-89.

15 Melin JA, Wijns W, Vanbutsele RJ, et al. Alternative diagnostic strategies for coronary artery disease in women: demonstration of the usefulness and efficiency of probability analysis. Circulation 1985;71:535-42.

16 Patterson RE, Horowitz SF, Eng C, et al. Can exercise electrocardiography and thallium-201 myocardial imaging exclude the diagnosis of coronary artery disease? Bayesian analysis of the clinical limits of exclusion and indications for coronary angiography. Am $\mathcal{f}$ Cardiol 1982 49:1127-35.

17 Lavey EM, Winkel RA. Continuing disability of patients with chest pain and normal coronary arteriograms. F Chron Dis 1979;32:191-6.

18 Ockene IS, Shay MJ, Alpert JS, Weiner BH, Dalen JE. Unexplained chest pain in patients with normal coronary arteriograms. A follow-up study of functional status. $N$ Engl $\mathcal{J}$ Med
$1980 ; 303: 1249-52$.

19 Bass C, Wade C, Hand D, Jackson G. Patients with angina with normal and near normal coronary arteries: clinical and psychosocial state 12 months after angiography. $\mathrm{Br}$ Med $\mathcal{f}$ 1983;287:

20 Ambrose JA. Unsettled indications for coronary angiography. Foumal of the American College of Cardiology 1984;3:1575-80.
21 Bruschke AVG, Proudfit WL, Sones FM. Progress study of 590 consecutive nonsurgical cases of coronary disease followed 5-9 years. Ventriculographic and other correlations. Circulation 1973;47:1154-63.

22 Morris SN, Phillips JF, Jordan JS, McHenry PL. Incidence and significance of decreases in systolic blood pressure during graded treadmill exercise testing. Am f Cardiol 1978; 41:221-7.

23 Sanmarco ME, Pontius S, Selvester RH. Abnormal blood pressure response and marked ischemic ST-segment depression as predictors of severe coronary artery disease. Circulation 1980;61 572-8.

24 Dagenais GR, Rouleau JR, Christen A, Fabia J. Survival of patients with a strongly positive exercise electrocardiogram. Circulation 1982;65:452-6.

25 Williams A. Econmics of coronary artery bypass grafting. Br Med $\mathcal{J}$ 1985;291:326-9.

\section{Landmarks in medicine}

A century ago in the United States scientific medicine scarcely existed. Postgraduate training was woefully undeveloped, and young American physicians seeking experience in research crossed the Atlantic to European centres, particularly in Germany. The foundation of Johns Hopkins Medical School in 1889, the creation of the Rockefeller Institute in the early years of this century, and the reforms in American medical education recommended by Abraham Flexner led to a scientific revolution in medical academic circles that was to establish the United States as the world leader in biomedical science in the modern era.

The fruits of that revolution were illustrated by a series of 51 articles published weekly in the Fournal of the American Medical Association from July 1983 to August 1984 in recognition of its centenary year and now collected into a single volume. ${ }^{1}$ Each of the 51 consists of an article originally published in the journal together with a contemporary commentary by an expert in the subject. The oldest contribution is the original description of dermatitis herpetiformis by Duhring in 1884; the most recent-appropriatelyaddresses that most contemporary of ethical issues, the nature of brain death. They form a truly remarkable collection, which include several contributions by men destined later to receive the accolade of the Nobel prize: Alexis Carrel's pioneer studies on vascular anastomosis and organ transplantation, Simon Flexner's transmission of acute poliomyelitis to monkeys, Peyton Rous's transfer of a malignant new growth with a cell free filtrate were all from the Rockefeller Institute in New York. Achievements from the Boston medical schools included Minot's and Murphy's treatment of pernicious anaemia with a special diet, Castle's classic studies on the intrinsic factor mechanism in the stomach, and the first successful homotransplantation of a kidney between identical twins by Merrill and his colleagues. The United States armed services contributed Walter Reed's immortal and courageous studies on the transmission of yellow fever, the use of penicillin in the treatment of meningitis, and the treatment of acute attacks of vivax malaria with chloroquine.

Fifty-one Landmark Articles in Medicine is a remarkable collection of outstanding firsts; it also includes the original description of Crohn's disease, Blalock and Taussig's pioneer surgical treatment of malformations of the heart, the first surgical ligation of a patent ductus arteriosus, the technique of closed chest cardiac massage developed at Johns Hopkins Hospital, and Blumberg's new antigen in leukaemia sera. The articles prompt two questions. Which real advances are apparent at the time an article is published-and to what extent are such advances recognised only in retrospect?

The collection shows that when an article relates to the introduction of a new and effective method of treatment-as 